\title{
Atividade sérica das enzimas AST, CK e GGT em cavalos Crioulos
}

\author{
Carina Franciscato(1), Sonia Terezinha dos Anjos Lopes ${ }^{(1)}$, Ângela Patrícia Medeiros Veiga ${ }^{(2)}$, \\ Danieli Brolo Martins ${ }^{(1)}$, Mauren Picada Emanuelli ${ }^{(1)}$ e Luiz Sergio Segala Oliveira ${ }^{(1)}$
}

\begin{abstract}
(1)Universidade Federal de Santa Maria, Centro de Ciências Rurais, Hospital de Clínicas Veterinárias, Dep. de Clínica de Pequenos Animais, Av. Roraima s/no, CEP 97105-900 Santa Maria, RS. E-mail: carinafranciscato@yahoo.com.br, sonia@smail.ufsm.br, doggycatz@yahoo.com.br, maurenvet@hotmail.com, segalaol@smail.ufsm.br (2)Universidade Federal do Rio Grande do Sul, Fac. de Veterinária, Av. Bento Gonçalves 9090, CEP 915040-000 Porto Alegre, RS. E-mail: angelavet@terra.com.br
\end{abstract}

Resumo - O objetivo deste trabalho foi verificar a influência da idade, sexo, manejo e estado gestacional sobre a atividade sérica das enzimas: aspartato aminotransferase (AST), creatina quinase (CK) e gama-glutamiltransferase (GGT) em cavalos da raça Crioula. Foram utilizados 142 eqüinos, divididos em seis grupos: potros até um ano de idade; cavalos adultos em regime de atividade livre; cavalos adultos em treinamento; machos adultos; fêmeas não gestantes; fêmeas gestantes. $\mathrm{O}$ valor da $\mathrm{CK}$ foi mais elevado em animais adultos do que em potros, o mesmo tendo ocorrido em animais em atividade livre, comparados a animais em treinamento. Fêmeas não gestantes apresentaram valores das enzimas CK e GGT maiores que os machos; o valor da CK em fêmeas gestantes foi mais elevado do que em fêmeas não gestantes. A idade, o sexo, o manejo e o estado gestacional influenciam a atividade sérica da CK, e o sexo influencia a atividade sérica da GGT.

Termos para indexação: bioquímica sérica, enzimas musculares, doenças hepáticas, miopatia.

\section{AST, CK and GGT enzymes serum activities in Crioulo horses}

\begin{abstract}
The objective of this work was to evaluate the influence of age, sex, management and pregnancy status on aspartate aminotransferase (AST), creatine kinase (CK) and gamma-glutamyltransferase (GGT) enzymes serum activities of Crioulo horses. One hundred and forty-two horses, divided into six group were analyzed: yearlings; free activity of adult horses; training adult horses; male adult horses; nonpregnant and pregnant females. The CK enzyme activity value was higher in adult horses than in yearlings, and the same result was found when comparing free activity and training horses. Nonpregnant females had higher values for CK and GGT comparing to male horses, and CK values were higher in pregnant comparing to nonpregnant females. Age, sex, management and pregnancy status influence on CK serum activity, and sex influences on GGT serum activity.
\end{abstract}

Index terms: serum biochemistry, muscular enzyme, hepatic disease, myopathy.

\section{Introdução}

Os sinais clínicos presentes em distintas alterações musculares são semelhantes e bastante inespecíficos; por isso, quando isolados, eles têm limitado valor diagnóstico, o que requer, freqüentemente, o uso de exames laboratoriais complementares. Entre as enzimas, cujas concentrações séricas devem ser determinadas quando de disfunções musculares, estão aspartato aminotransferase (AST) e a creatina quinase (CK) (Da Cás et al., 2000). Além disso, a patogenia de doenças hepáticas nos animais domésticos é muito complexa, por isso, o diagnóstico dessas enfermidades também envolve testes bioquímicos, entre os quais o uso da enzima gama-glutamiltransferase (GGT) como marcador sérico primário, para doenças do sistema hepatobiliar associadas com colestase (Tennant, 1997).

A aspartato aminotransferase (AST) é uma enzima citoplasmática e mitocondrial, presente em vários tecidos como fígado, músculos esquelético e cardíaco (Tennant, 1997; Frape, 1998). Tennant (1997) salienta que em todas as espécies domésticas a atividade da AST é alta no fígado, portanto, na lesão hepática aguda ou crônica, a atividade sérica de AST está elevada. Segundo Cardinet (1997), essa enzima também tem sido usada como auxílio diagnóstico em alterações musculares dos animais domésticos. Os eqüinos podem apresentar um aumento nos valores de AST em conseqüência da miopatia ou lesão hepática, e a principal razão para se 
incluir a AST no perfil bioquímico de eqüinos é a tentativa de detectar doença hepatocelular (Stockham, 1995).

Creatina quinase (CK) é a enzima mais amplamente utilizada para determinação de alterações musculares dos animais domésticos, e é considerada um indicador altamente sensível e específico de lesão muscular, já que os principais tecidos fontes dessa enzima são as fibras musculares (Cardinet, 1997).

Embora a CK seja mais específica para a necrose muscular do que a AST, Cardinet (1997) e Perez et al. (1997) salientam que a determinação simultânea de ASTe CK em eqüinos representa valioso potencial diagnóstico e ajuda no prognóstico, em razão das diferentes taxas de desaparecimento de suas atividades no soro ou no plasma. Segundo Cardinet (1997), a elevação da atividade sérica da CK indica se a necrose muscular é ativa ou ocorreu recentemente; a persistente elevação de CK indica que a necrose muscular continua ativa, e AST elevada, por causa da necrose muscular, acompanhada por atividade decrescente ou normal de CK, indica que a necrose muscular não é mais ativa. Frape (1998) relata que a CK tem uma meia-vida de menos de 24 horas, enquanto a AST tem uma meia-vida de sete a oito dias.

Ao analisar enzimas musculares e hepatobiliares, Stockham (1995) cita que um aumento nos valores séricos de AST, com uma atividade normal de CK, sugere que o aumento da AST ocorre em razão de doença hepatobiliar e não em razão do dano muscular, entretanto, deve-se ter cautela nessa conclusão, já que a meia-vida da CK circulante é menor que a da AST.

A GGT é uma enzima de membrana, associada a numerosos tecidos (Meyer et al., 1995) como fígado, rins, pâncreas e intestino (Tennant, 1997). A maior quantidade de GGT celular está nas células tubulares renais e no epitélio dos ductos biliares (Kramer \& Hoffmann, 1997); sua atividade érelativamente alta no fígado de bovinos, eqüinos, ovinos e caprinos, com menor atividade nos caninos e felinos (Tennant, 1997). Porém, a colestase provoca aumento na atividade sérica desta enzima, em todas as espécies (Meyer et al., 1995; Kramer \& Hoffmann, 1997), com melhor utilidade diagnóstica que a fosfatase alcalina (FA), em eqüinos e ruminantes (Meyer et al., 1995), em razão do amplo intervalo de referência da FA nessas espécies (Duncan et al., 1994); mesmo que a GGT esteja presente em muitos tecidos, elevações na sua atividade sérica são observadas primariamente em desordens hepáticas (Tennant, 1997).

Este trabalho teve como objetivo verificar a influência da idade, sexo, manejo e estado gestacional sobre a atividade sérica das enzimas AST, CK e GGT em cavalos Crioulos.

\section{Material e Métodos}

Foram utilizados 142 eqüinos da raça Crioula, submetidos a exame clínico para constatar a higidez, previamente à coleta de sangue. Os animais foram divididos em seis grupos, de acordo com a idade, atividade ou estado gestacional. Os grupos formados foram: 1) potros entre seis meses e um ano de idade (n, 41); 2) cavalos adultos, entre dois e 15 anos, machos ou fêmeas, em regime de atividade livre (n, 35); 3) cavalos adultos, entre dois e 15 anos, machos ou fêmeas, em treinamento (n, 27); 4) cavalos adultos, entre dois e 15 anos, machos (n, 28); 5) cavalos adultos, entre dois e 15 anos, fêmeas não gestantes (n, 34); 6) cavalos adultos, entre dois e 15 anos, fêmeas gestantes (n, 42). Os animais provieram de várias propriedades da região central do Rio Grande do Sul.

De cada animal foram coletados $10 \mathrm{~mL}$ de sangue, sempre no período da manhã, por venopunção da jugular em tubo de colheita a vácuo. O soro foi separado por centrifugação a $2.500 \mathrm{rpm}$, por 10 minutos, e mantido a $-20^{\circ} \mathrm{C}$ até a realização das análises.

As provas bioquímicas foram efetuadas por meio de processo cinético, em analisador semi-automático, com kits comerciais das enzimas AST, CK e GGT.

A análise estatística foi realizada com o SAS Institute (1997). Os dados foram submetidos à análise de variância, e as médias foram comparadas pelo teste de Tukey a 5\% de probabilidade.

\section{Resultados e Discussão}

Os resultados obtidos para as enzimas CK, AST e GGT, de acordo com os grupos experimentais, estão indicados nas Tabelas 1, 2, 3 e 4.

Não houve diferença significativa nos valores médios da AST nos grupos estudados (Tabelas 1, 2, 3 e 4), o que discorda de Stockham (1995), que cita que os valores desta enzima são mais elevados em potros que nos animais adultos. Bauer et al. (1984) e Da Cás et al. (2001) relatam que, nas primeiras semanas depois do parto, ocorre elevação gradual dos valores de AST, atribuída ao aumento da atividade muscular dos potros nesse período. No entanto, os potros descritos neste trabalho tinham idade superior a seis meses, o que pode explicar porque os valores não diferiram, significativamente, entre os potros e os animais do grupo 2 (Tabela 1).

A ausência de diferença significativa nos valores de AST, entre os animais em treinamento (grupo 2) e os 
animais em atividade livre (grupo 3), pode ser justificada pelo fato de que os níveis dessa enzima são variáveis durante o treinamento, pois os efeitos do exercício sobre sua concentração dependem do estado de saúde dos animais, da intensidade e duração do exercício ao qual são submetidos, bem como do ambiente (Da Cás et al., 2000).

Na Tabela 1, observa-se também que em animais adultos, em regime de atividade livre (grupo 2), o valor médio da enzima CK foi significativamente mais elevado do que nos potros (grupo 1). Para Da Cás et al. (2001), a concentração dessa enzima permanece relativamente constante do nascimento até o primeiro ano de idade. Assim, esta diferença pode ser atribuída ao aumento da idade. Cardinet (1997) explica que nos animais domésticos, os valores normais de CK podem variar com a atividade física, idade e sexo. É importante salientar que esta é uma enzima citoplasmática sujeita à rápida liberação na circulação, como resultado de pequenas alterações celulares (Duncan et al., 1994; Stockham, 1995), que pode atingir um pico de concentração sangüínea de 6 a 12 horas após a lesão (Frape, 1998).

Os animais em treinamento (grupo 3) apresentaram valores médios para CK significativamente menores do

Tabela 1. Valores médios, máximos, mínimos e desvios-padrão das enzimas CK, AST e GGT, de eqüinos da raça Crioula, de acordo com a idade ${ }^{(1)}$.

\begin{tabular}{ccccr}
\hline Grupo & $\mathrm{N}$ & CK & AST & GGT \\
\hline 1 & 41 & $184,81 \mathrm{~b}$ & $179,56 \mathrm{a}$ & $2,68 \mathrm{a}$ \\
& & $(51-363)$ & $(94-240)$ & $(1-4)$ \\
& & $\pm 77,25$ & $\pm 38,61$ & $\pm 1,17$ \\
\hline 2 & 35 & $242,94 \mathrm{a}$ & $199,66 \mathrm{a}$ & $2,65 \mathrm{a}$ \\
& & $(103-467)$ & $(120-309)$ & $(1-5)$ \\
& & $\pm 111,25$ & $\pm 47,10$ & $\pm 1,30$ \\
\hline
\end{tabular}

${ }^{(1)}$ Letras diferentes, em cada coluna, indicam diferença significativa $(\mathrm{p}<0,05)$ pelo teste de Tukey.

Tabela 2. Valores médios, máximos, mínimos e desvios-padrão das enzimas CK, AST e GGT, de eqüinos da raça Crioula, em regime de atividade livre e em treinamento ${ }^{(1)}$.

\begin{tabular}{ccccc}
\hline Grupo & $\mathrm{N}$ & $\mathrm{CK}$ & AST & GGT \\
\hline 2 & 35 & $242,94 \mathrm{a}$ & $199,66 \mathrm{a}$ & $2,65 \mathrm{a}$ \\
& & $(103-467)$ & $(120-309)$ & $(1-5)$ \\
& & $\pm 111,25$ & $\pm 47,10$ & $\pm 1,30$ \\
\hline 3 & 27 & $159,81 \mathrm{~b}$ & $209,67 \mathrm{a}$ & $2,77 \mathrm{a}$ \\
& & $(77-311)$ & $(99-382)$ & $(1-5)$ \\
& & $\pm 61,20$ & $\pm 81,41$ & $\pm 1,25$ \\
\hline
\end{tabular}

${ }^{(1)}$ Letras diferentes, em cada coluna, indicam diferença significativa $(\mathrm{p}<0,05)$ pelo teste de Tukey. que os valores apresentados pelos animais em regime de atividade livre, representados pelo grupo 2 (Tabela 2). A não elevação da CK, nos animais em treinamento, concorda com os resultados de Ribeiro et al. (2004) que, em estudo com eqüinos submetidos a provas de resistência, não encontraram diferença significativa entre os valores de CK antes e após o exercício. Esses resultados podem ser explicados pelo fato de que um programa de treinamento adequado, ajustado ao condicionamento físico do eqüino, não leva a um aumento acentuado na concentração das enzimas de função muscular (Da Cás et al., 2000). Portanto, sugere-se que esses animais estariam adaptados ao programa de exercícios a que eram submetidos, conforme citam Ribeiro et al. (2004), tendo diferido dos eqüinos em fase de adaptação ao treinamento que apresentam elevação dos valores séricos desta enzima (Da Cás et al., 2000), e também daqueles animais nos quais a avaliação enzimática é realizada logo após o exercício, pois segundo Rose et al. (1983), a CK apresenta elevação rápida após o exercício máximo.

As fêmeas não gestantes apresentaram valor médio da enzima CK significativamente maior do que os machos (Tabela 3). Esse resultado está de acordo com

Tabela 3. Valores médios, máximos, mínimos e desvios-padrão das enzimas CK, AST e GGT, de eqüinos da raça Crioula, de acordo com o sexo ${ }^{(1)}$.

\begin{tabular}{ccccc}
\hline Grupo & $\mathrm{N}$ & CK & AST & GGT \\
\hline 4 & 28 & $164,64 \mathrm{~b}$ & $196,18 \mathrm{a}$ & $2,28 \mathrm{~b}$ \\
& & $(77-311)$ & $(99-371)$ & $(1-5)$ \\
& & $\pm 61,49$ & $\pm 65,50$ & $\pm 1,18$ \\
\hline 5 & 34 & $241,41 \mathrm{a}$ & $210,47 \mathrm{a}$ & $3,05 \mathrm{a}$ \\
& & $(77-467)$ & $(110-382)$ & $(1-5)$ \\
& & $\pm 114,27$ & $\pm 62,84$ & $\pm 1,25$ \\
\hline
\end{tabular}

${ }^{(1)}$ Letras diferentes, em cada coluna, indicam diferença significativa $(\mathrm{p}<0,05)$ pelo teste de Tukey.

Tabela 4. Valores médios, máximos, mínimos e desvios-padrão das enzimas CK, AST e GGT, de eqüinos da raça Crioula, em fêmeas gestantes e não gestantes ${ }^{(1)}$.

\begin{tabular}{ccrcc}
\hline Grupo & $\mathrm{N}$ & $\mathrm{CK}$ & $\mathrm{AST}$ & GGT \\
\hline 5 & 34 & $241,41 \mathrm{~b}$ & $210,47 \mathrm{a}$ & $3,05 \mathrm{a}$ \\
& & $(77-467)$ & $(110-382)$ & $(1-5)$ \\
& & $\pm 114,27$ & $\pm 62,84$ & $\pm 1,25$ \\
\hline 6 & 42 & $361,12 \mathrm{a}$ & $194,74 \mathrm{a}$ & $2,57 \mathrm{a}$ \\
& & $(77-596)$ & $(73-288)$ & $(1-7)$ \\
& & $\pm 127,50$ & $\pm 45,30$ & $\pm 1,25$ \\
\hline
\end{tabular}

${ }^{(1)}$ Letras diferentes, em cada coluna, indicam diferença significativa $(\mathrm{p}<0,05)$ pelo teste de Tukey. 
Harris et al. (1990) e Da Cás et al. (2000). Da Cás et al. (2000) sugerem que este resultado pode estar associado à atividade enzimática mais elevada e/ou à remoção mais lenta da circulação, ou ainda, à maior sensibilidade a agressões que alteram a permeabilidade das fibras musculares, o que resulta em maior incidência de rabdomiólise em fêmeas.

O valor médio da CK para fêmeas gestantes foi significativamente mais elevado do que para fêmeas não gestantes (Tabela 4). Análises de tecidos humanos indicaram que atividades significativas de CK estão presentes também no útero, entre outros órgãos (Cardinet, 1997), o que pode explicar o fato de fêmeas gestantes apresentarem maior atividade da enzima do que fêmeas não gestantes.

Para Warko \& Bostedt (1991) e Meyer et al. (1995), o colostro e o leite contêm uma quantidade deGGT notavelmente alta, conseqüentemente, os animais em amamentação apresentam elevada atividade sérica dessa enzima. Petterson \& Brown (1986) explicam que potros jovens têm maiores valores séricos de GGT do que suas mães. No entanto, neste trabalho, os valores médios dessa enzima, nos potros, não diferiram significativamente dos valores encontrados para os animais do grupo 2 (Tabela 1), possivelmente pelo fato de esses potros não estarem mais ingerindo colostro, já que suas idades variavam de seis a 12 meses.

Houve diferença significativa para os resultados da GGT somente entre os grupos 4 e 5 (Tabela 3), em que as fêmeas não gestantes apresentaram valores mais elevados do que os machos. Isto contraria os dados de Kaplan et al. (2003), que ao trabalhar com seres humanos, encontraram valores normais da GGT mais altos nos homens do que nas mulheres.

A atividade média da enzima AST manteve-se dentro dos intervalos de referência descritos para a espécie eqüina (Duncan et al., 1994; Rose \& Hodgson, 1994; Meyer \& Harvey, 1998), e estes valores estão abaixo dos referenciados por Meyer et al. (1995) e Kaneko et al. (1997). Os valores médios, encontrados na respectiva pesquisa, para a enzima CK, permaneceram dentro dos intervalos de referência citados por Duncan et al. (1994) e Rose \& Hodgson (1994), embora os valores máximos, dos grupos 1, 2, 5 e 6 estejam acima dos valores máximos mensurados pelos referidos autores. Os valores médios dessa enzima ficaram acima dos intervalos descritos por Meyer et al. (1995) e Kaneko et al. (1997). Para a enzima GGT, os valores médios ficaram abaixo dos intervalos referenciados por Duncan et al. (1994), Meyer et al. (1995), Kaneko et al. (1997) e Meyer \& Harvey (1998) (Tabela 5). As diferenças encontradas por esses autores indicam a necessidade de os laboratórios obterem seus próprios valores de referência.
Tabela 5. Intervalos de referência das enzimas CK, AST e GGT, descritos para a espécie eqüina.

\begin{tabular}{lccc}
\hline Autores & CK (U/L) & AST (U/L) & GGT (U/L \\
\hline Duncan et al. (1994) & $60-330$ & $160-412$ & $6-32$ \\
Rose \& Hodgson (1994) & $100-300$ & $150-400$ & - \\
Meyer et al. (1995) & $86-140$ & $226-366$ & $4-13,4$ \\
Kaneko et al. (1997) & $2,4-23,4$ & $226-366$ & $4,3-13,4$ \\
Meyer \& Harvey (1998) & $113-133$ & $152-294$ & $9-25$ \\
\hline
\end{tabular}

\section{Conclusões}

1. A idade, o sexo, o manejo e o estado gestacional são fatores que têm influência sobre a atividade sérica da enzima creatina quinase.

2. A atividade sérica da enzima gamaglutamiltransferase é influenciada pelo sexo.

\section{Agradecimentos}

Ao professor José Henrique Souza da Silva, do Dep. de Zootecnia da Universidade Federal de Santa Maria, pela orientação nas análises estatísticas.

\section{Referências}

BAUER, J.E.; HARVEY, J.W.; ASQUITH, R.L. Clinical chemistry reference values of foals during the first year of life. Equine Veterinary Journal, v.16, p.361-363, 1984.

CARDINET, G.H. Skeletal muscle function. In: KANEKO, J.J.; HARVEY, J.W.; BRUSS, M.L. Clinical Biochemistry of domestic animals. $5^{\text {th }}$ ed. London: Academic Press, 1997. p.407-440.

DACÁS, E.L.; BRASS, K.E.; GREIG, C.R.; DEPRÁ, N.M.; SILVA, C.A.M. Concentrações de creatino quinase, aspartato aminotransferase e dehidrogenase lática em potros do nascimento até os seis meses de idade. Ciência Rural, v.31, p.1003-1006, 2001.

DA CÁS, E.L.; ROSAURO, A.C.; SILVA, C.A.M.; BRASS, K.E. Concentração sérica das enzimas creatinoquinase, aspartato aminotransferase e dehidrogenase lática em eqüinos da raça Crioula. Ciência Rural, v.30, p.625-629, 2000.

DUNCAN, J.R.; PRASSE, K.W.; MAHAFFEY, E.A. Veterinary laboratory medicine: Clinical Pathology. $3^{\text {rd }}$ ed. Iowa: Iowa State University, 1994. 300p.

FRAPE, D. Equine nutrition \& feeding. $2^{\text {nd }}$ ed. Oxford: Blackwell Science, 1998. 564p.

HARRIS, P.A.; SNOW, D.H.; GREET, T.R.; ROSSDALE, P.D. Some factors influencing plasma AST/CK activities in thoroughbred racehorses. Equine Veterinary Journal, v.9, p.66-71, 1990.

KANEKO, J.J.; HARVEY, J.W.; BRUSS, M.L. Appendixes. In: KANEKO, J.J.; HARVEY, J.W.; BRUSS, M.L. Clinical Biochemistry of domestic animals. $5^{\text {th }} \mathrm{ed}$. London: Academic Press, 1997. p.885-906. 
KAPLAN, L.A.; PESCE, A.J.; KAZMIERCZAK, S.C. Clinical Chemistry: theory, analysis, correlation. $4^{\text {th }}$ ed. St. Louis: Mosby, 2003. 1179p.

KRAMER, J.W.; HOFFMANN, W.E. Clinical Enzymology. In: KANEKO, J.J.; HARVEY, J.W.; BRUSS, M.L. Clinical Biochemistry of Domestic Animals. $5^{\text {th }}$ ed. London: Academic Press, 1997. p.303-325.

MEYER, D.J.; COLES, E.H.; RICH, L.J. Medicina de laboratório veterinário: interpretação e diagnóstico. São Paulo: Roca, 1995. 308p.

MEYER, D.J.; HARVEY, D.J. Veterinary laboratory medicine: interpretation \& diagnosis. Philadelphia: W. B. Saunders, 1998. 373p.

PEREZ, R.; GARCIA, M.; CABEZAS, I.; GUZMAN, R.; MERINO, V.; VALENZUELA, S.; GONZALEZ, C. Actividad física y cambios cardiovasculares y bioquímicos del cavallo chileno a la competencia de rodeo. Archivos de Medicina Veterinaria, v.29, p.221-234, 1997.

PETTERSON, W.H.; BROWN, C.M. Increase of serum $\gamma$-glutamyltransferase in neonatal standardbred foals. American Journal of Veterinary Research, v.47, p.2461-2463, 1986.

RIBEIRO, C.R.; MARTINS, E.A.N.; RIBAS, J.A.S.; GERMINARO, A. Avaliação de constituintes séricos em eqüinos e muares submetidos à prova de resistência de 76 km, no Pantanal do Mato Grosso, Brasil. Ciência Rural, v.34, p.1081-1086, 2004.

ROSE, R.J.; HODGSON, D.R. Hematology and Biochemistry. In: HODGSON, D.R.; ROSE, R.J. The atlhetic horse: principles and practice of equine sports medicine. Philadelphia: Saunders, 1994. p.63-78.

ROSE, R.J.; HODGSON, D.R.; SAMPSON, D. Changes in plasma biochemistry in horses competing in a $160 \mathrm{~km}$ endurace ride. Australian Veterinary Journal, v.60, p.101-105, 1983.

SAS INSTITUTE (Cary, Estados Unidos). SAS/STAT user's guide: statistics. Version 6.11. Cary, 1997. v.2. 943p.

STOCKHAM, S.L. Interpretation of equine serum biochemical profile results. Veterinary Clinics of North America: Equine Practice, v.11, p.391-414, 1995.

TENNANT, B.C. Hepatic function. In: KANEKO, J.J.; HARVEY, J.W.; BRUSS, M.L. Clinical Biochemistry of Domestic Animals. $5^{\text {th }}$ ed. London: Academic Press, 1997. p.327-352.

WARKO, G.; BOSTEDT, H. GGT activity in the blood serum of newborn foals after the absorption of a non-species specific colostrum preparation. Berliner und Munchener Tierarztliche Wochenschrift, v.104, p.221-223, 1991. 